\title{
Quantifying the model structural error in carbon cycle data assimilation systems
}

\author{
S. Kuppel, F. Chevallier, and P. Peylin \\ Laboratoire des Sciences du Climat et de l'Environnement, UMR8212, CEA-CNRS-UVSQ, \\ 91191 Gif-sur-Yvette cedex, France \\ Correspondence to: S. Kuppel (sylvain.kuppel@1sce.ipsl.fr) \\ Received: 6 July 2012 - Published in Geosci. Model Dev. Discuss.: 14 August 2012 \\ Revised: 21 November 2012 - Accepted: 26 November 2012 - Published: 11 January 2013
}

\begin{abstract}
This study explores the impact of the structural error of biosphere models when assimilating net ecosystem exchange (NEE) measurements or $\mathrm{CO}_{2}$ concentration measurements to optimise uncertain model parameters within carbon cycle data assimilation systems (CCDASs). This error has been proven difficult to identify and is often neglected in the total uncertainty budget. We propose a simple method which is derived from the model-minus-observation mismatch statistics. This diagnosis is applied to a state-ofthe-art biogeochemical model using measurements of the net surface $\mathrm{CO}_{2}$ flux at twelve sites located in temperate, deciduous, broadleaf forests. We find that the structural model error in the NEE space has a standard deviation of 1.5 to $1.7 \mathrm{gC} \mathrm{m}^{-2} \mathrm{~d}^{-1}$, without a significant correlation structure beyond the lag of a few days, and a large spatial structure that can be approximated with an exponential decay of efolding length of $500 \mathrm{~km}$. In the space of concentrations, its characteristics are commensurate with the transport errors, both for surface air sample measurements and total column measurements. The inferred characteristics are confirmed by complementary optimality diagnostics performed after sitescale parameter optimisations.
\end{abstract}

\section{Introduction}

Carbon cycle data assimilation systems (CCDASs) optimise internal parameters of dynamical models of the global carbon cycle (Kaminski et al., 2002; Rayner et al., 2005; Scholze et al., 2007), using carbon-cycle related observations. Like atmospheric inverse models (e.g., Gurney et al., 2002), they allow the inferring of the space-time distribution of surface
$\mathrm{CO}_{2}$ fluxes from observations, but their underlying processbased model allows them to use a much larger diversity of measurements, e.g., local flux measurements (Kato et al., 2012; Knorr et al., 2010), satellite observations of vegetation activity (Kaminski et al., 2012; Kato et al., 2012; Knorr et al., 2010) or biomass inventories. Their model prognostic equations can also spread the observational information well beyond the temporal and spatial cover of the measurements (Scholze et al., 2007; Rayner et al., 2011). The downside of this strategy is the interference from the errors of the model equations in the data assimilation process. Indeed the choice of a process-based approach imposes these equations as a strong constraint to the inversion, even though they are an imperfect representation of the biophysical and ecophysiological mechanisms that drive terrestrial ecosystems.

Bayes' theorem provides a rigorous paradigm to build such CCDASs. Its application implies characterising the uncertainties of each CCDAS component:

- the measurement error;

- the model error, which stems from inappropriate equation forms or from missing processes in the carboncycle model structure;

- the error brought by the meteorological and vegetation forcing data, here considered as a part of the model error;

- the parameter error, arising from inadequate knowledge about a series of parameters.

Following the usual convention, we call observation error the sum of the measurement error and of the model error (i.e., the first three items in the above list). 
Even within the basic assumption of normally-distributed errors, this characterisation involves potentially large error covariance matrices, at least for the model and the observation errors.

The present study aims at providing a method to explicitly quantify the error of process-based terrestrial models, in particular, for global CCDASs. The conclusions also apply to site-scale parameter optimisation schemes. Denoting as "prior" the state of the carbon-cycle model before any observational constraint, we propose to analyse the statistics of the prior residuals (observations-minus-prior simulations) with the help of the assigned prior parameter uncertainties projected in the observation space. Within the Bayesian framework, these two pieces of information and the observation error, which is the summed contribution of model and measurement errors, are linked together. We apply this method to the global biosphere model ORganising Carbon and Hydrology In Dynamic EcosystEms (ORCHIDEE, Krinner et al., 2005) in temperate deciduous broadleaf forests, using measurements of the daily net ecosystem exchange (NEE) flux at twelve eddy-covariance flux measurement sites as observable quantity. We take advantage from the previous studies that have characterised the uncertainties of these measurements (e.g., Richardson et al., 2008). The inferred structure of the observation (model + measurement) error on the modelled net carbon fluxes is then projected in the space of atmospheric concentrations in order to characterise its structure when assimilating concentration measurements with a CCDAS.

In Sect. 2, we present the biogeochemical model and the flux data used in this study, as well as the methodology of the different diagnoses and evaluations. In Sect. 3, the presentation of the results is divided into five parts: analysis of the statistics of the prior residuals and the prior-parameter error, diagnosis of the temporal structure of the observation error, posterior evaluation at the site level, identification of the spatial structure of the observation error and projection in the space of atmospheric concentrations. Finally, the results are discussed in Sect. 4.

\section{Methods}

\subsection{Flux data}

The observations of $\mathrm{CO}_{2}$ surface fluxes used in this study have been made with the eddy-covariance technique. This method uses the covariance between fluctuations of turbulent vertical wind (eddies) and the scalar of interest (e.g., $\mathrm{CO}_{2}$ mixing ratio) to calculate vertical fluxes of carbon, water and energy within atmospheric boundary layers (Aubinet et al., 2000). The measurements have a footprint of a few hectares and notably rely on the assumption of a well-mixed, fully turbulent boundary layer above a flat landscape. At present, flux towers are considered as the reference standard for $\mathrm{CO}_{2}$ surface flux measurement, and there has been an effort to develop a global network of them across representative biomes in the FluxNet database (Baldocchi et al., 2001; Baldocchi, 2008). More specifically, the LaThuile archive contains gap-filled measurements of half-hourly net carbon flux (NEE) collected using a standardised protocol (Papale et al., 2006), as well as the corresponding meteorological data later used as an input for the ORCHIDEE model. We selected 12 flux tower stations in the Northern Hemisphere located in temperate deciduous broadleaf forests, which correspond to one of the plant functional types (PFT) used in the ORCHIDEE model (Table A1). From this half-hourly data we compute daily means, in order to take advantage of the rapidly-declining autocorrelation of gap-filled halfhourly fluxes (see Fig. 5a in Lasslop et al., 2008).

\subsection{Terrestrial model}

The biogeochemical vegetation model ORCHIDEE calculates the water, energy and carbon fluxes between the land ecosystems and the atmosphere. The exchange of carbon and water during photosynthesis and the energy balance are simulated on a half-hourly basis, while carbon allocation, autotrophic respiration, foliar onset and senescence, mortality and soil organic matter decomposition are processes computed on a daily time step. The ORCHIDEE processes and ruling equations have been extensively described by Krinner et al. (2005). In this study, ORCHIDEE is used in a "gridpoint mode" at one given location at a time, forced with the corresponding local half-hourly gap-filled meteorological measurements obtained at the flux towers. At each location, the modelled carbon pools are initially brought to equilibrium by cycling the meteorological forcing over a long period, so that the net carbon flux nears zero. The a priori configuration of the model is the one used in a series of data assimilation studies (Kuppel et al., 2012; Santaren et al., 2007; Verbeeck et al., 2011). A state vector $\boldsymbol{x}$ of 26 key parameters is considered (see Table B1). A physically-based variation range has been defined for each parameter. The prior standard deviations of the model parameter errors are assigned in the $\mathbf{B}$ matrix as $1 / 6$ of this range.

\subsection{Diagnoses}

In this study, notations for vectors and matrices are as follows: subscripts refer to contributions (e.g., model, measurements...), superscripts refer to contexts (e.g., prior state, posterior state), and hats (" $\wedge$ ") to estimates. Defining the prior state $\boldsymbol{x}^{\text {prior }}$ as the vector of prior parameters, the prior model output (here, the daily NEE) is given by $H\left(x^{\text {prior }}\right)$, where $H$ is the observation operator. Assuming the linearity of the model in the vicinity of the prior state, we introduce the Jacobian matrix $\mathbf{H}$ that corresponds to the linearised version of $H$. With normally distributed and uncorrelated 
prior-parameter and observation errors, we can write (e.g., Desroziers et al., 2005):

$\mathbf{H B H} \mathbf{H}^{\mathrm{T}}+\mathbf{R}=\mathbf{D}$.

$\mathbf{H B H}^{\mathrm{T}}$ is the projection of the prior-parameter error covariance matrix $\mathbf{B}$ in the observation space, $\mathbf{R}$ is the covariance matrix of the observations errors (i.e., model errors + measurement errors), and $\mathbf{D}$ is the covariance matrix for the distribution of the residuals from the prior model $\boldsymbol{d}^{\text {o-prior }}$ (i.e., the observation-minus-model mismatch), defined as

$\boldsymbol{d}^{\mathrm{o}-\text { prior }}=\boldsymbol{y}^{\mathrm{o}}-H\left(\boldsymbol{x}^{\text {prior }}\right)$,

where $\boldsymbol{y}^{\mathrm{o}}$ is the observation vector (daily NEE in our case). Following the distinction made in Sect. 1, $\mathbf{R}$ is composed of two terms: $\mathbf{R}_{\text {meas }}$ the covariance matrix of the measurement error and $\mathbf{R}_{\text {mod }}$ the covariance matrix of the model error. Their respective contribution to the total observation error budget is discussed in Sect. 3 .

An additional diagnosis makes use of the optimised model state, i.e., the NEE fluxes after the optimisation of the model parameters $\boldsymbol{x}$ (see the inversion procedure in Sect. 2.4) to directly derive an estimate of $\mathbf{R}$ :

$\hat{\mathbf{R}}^{\text {post }}=\mathbf{F}$,

where $\mathbf{F}$ is the covariance between the prior residuals $\boldsymbol{d}^{\mathrm{o}-\text { prior }}$ (see Eq. 2) and the posterior residuals $\boldsymbol{d}^{\text {o-post }}$. The latter is defined as

$\boldsymbol{d}^{\mathrm{o}-\text { post }}=\boldsymbol{y}^{\mathrm{o}}-H\left(\boldsymbol{x}^{\text {post }}\right)$,

where $H\left(x^{\text {post }}\right)$ is the model output calculated at the optimised state $x^{\text {post }}$. The demonstration of the relation in Eq. (3) is given in Appendix A.

The prior and posterior diagnoses proposed in Eqs. (1) and (3) are respectively the starting points toward a prior estimation of the covariance matrix of observation errors (i.e., model errors + measurement errors) $\hat{\mathbf{R}}^{\text {prior }}$, and a posterior estimation $\hat{\mathbf{R}}^{\text {post }}$. Appendix B describes the application of both diagnoses at each flux measurement site, where for simplicity and to increase statistical significance we consider errors to be stationary in time, i.e., characterised by a single time lag. We acknowledge that this is a strong assumption for modelled carbon fluxes affected by significant seasonal variations, and this limitation should be kept in mind throughout the analysis of the results.

\subsection{Data assimilation system}

The site-scale inversions of the ORCHIDEE parameters are independently performed at each of the sites listed in Table A1, with a variational data assimilation system. The optimised parameters are listed in Table B1, while a more detailed description of the assimilation system can be found in
Kuppel et al. (2012). Briefly, we define a Bayesian cost function $J$,

$$
\begin{aligned}
J(\boldsymbol{x})= & \frac{1}{2}\left[\left(\boldsymbol{y}^{\mathrm{o}}-H(\boldsymbol{x})\right)^{\mathrm{T}} \boldsymbol{R}^{-1}\left(\boldsymbol{y}^{\mathrm{o}}-H(\boldsymbol{x})\right)\right. \\
& \left.+\left(\boldsymbol{x}-\boldsymbol{x}^{\text {prior }}\right)^{\mathrm{T}} \boldsymbol{B}^{-1}\left(\boldsymbol{x}-\boldsymbol{x}^{\text {prior }}\right)\right],
\end{aligned}
$$

where all the terms have been defined in the previous section. The cost function is minimised iteratively using a gradientbased approach, and the boundaries can be explicitly prescribed for each parameter in the minimisation algorithm. At each iteration, the gradient of the cost function is computed with respect to all parameters, using the tangent linear version of the model - except for threshold phenological parameters where a finite-differences approach is used. Note that for the computation of spatial statistics between sites (Sect. 3.4), the assimilation system is used in the "multi-site" mode described in Kuppel et al. (2012), where all sites are used simultaneously to derive common parameter values.

\subsection{Projection in the space of atmospheric concentrations}

The observation errors of the biosphere model, $\mathbf{R}$, associated to the Net Ecosystem Exchange of carbon (NEE) affect the assimilation of concentration measurements within a global CCDAS, like the errors of the atmospheric transport models affect the assimilation of such measurements within atmospheric inversions (e.g., Gurney et al., 2002). To quantify this impact, we project $\mathbf{R}$ in the space of atmospheric mixing ratios using the LMDZ atmospheric transport model (Hourdin et al., 2006) at global horizontal resolution $2.5 \times 3.75 \mathrm{deg}^{2}$ (latitude, longitude). Mathematically, we compute $\mathbf{T R T}^{\mathrm{T}}$, with $\mathbf{T}$ the Jacobian matrix of the transport model. In practice, we use an ensemble approach for this, rather than the direct sandwich product, as described in Chevallier et al. (2007). We consider two types of observations. The first one is the measurement of mixing ratios of $\mathrm{CO}_{2}$ collected in flask air samples or performed in situ by automatic analysers. We use the observation time-space sampling of the database gathered by Chevallier et al. (2011) for year 2010, which includes 91 stations over all oceans and continents. The second type of measurement is the column-averaged dry air mole fractions of $\mathrm{CO}_{2}$ (hereafter $X_{\mathrm{CO}_{2}}$ ) retrieved from surface stations (Wunch et al., 2011) or from space (e.g., Crisp et al., 2012). We use the time-space sampling of the quality-controlled retrievals from the Japanese Greenhouse gases Observing SATellite (GOSAT) made by NASA's Atmospheric $\mathrm{CO}_{2}$ Observations from Space (ACOS) project (O'Dell et al., 2012; Crisp et al., 2012). 


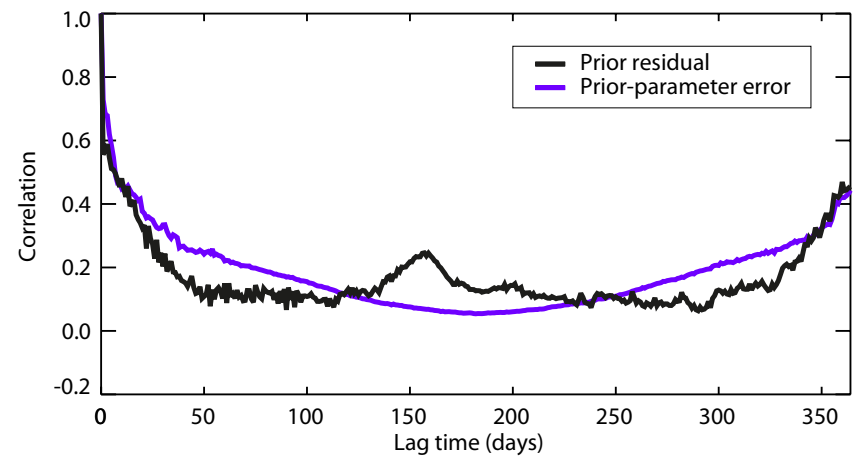

Fig. 1. All-site median of the autocorrelation of the residuals from the prior ORCHIDEE model (black, corresponding to D in Eq. 1) and of the prior-parameter error projected in the flux space (purple, corresponding to $\mathbf{H B H}^{\mathrm{T}}$ in Eq. 1), as functions of the time lag, for daily NEE.

\section{Results}

\subsection{Temporal structure of the prior residual and of the prior-parameter error}

Figure 1 shows the temporal autocorrelation structure of the prior residual (observation minus simulation) and of the prior-parameter error projected in the observation space (first term of Eq. 1), for the different FluxNet sites. The two curves displayed here represent the all-site median values, using 1day bins. The correlation structure reveals a similar seasonal pattern in both cases, with ever-positive values, larger at short lags and at lags close to one year. For the parameter error, the moderately high correlation at the one year lag $(0.44)$ indicates that inappropriate parameter values controlling seasonal processes (e.g., the maximum photosynthetic capacity) affect the seasonal pattern of NEE in the same direction each year. For the prior model-data residuals, in depth analyses of the results reveals that systematic NEE differences occur each year for specific seasons. For instance, the simulated winter NEE (mainly heterotrophic respiration for the chosen ecosystem) is overestimated each year at most sites, partly because the model was brought to steady state (see Kuppel et al., 2012).

The autocorrelation of the prior-parameter error (projected in the flux space) is generally larger than that of the prior residual. The all-site correlation of the prior residual falls below 0.5 after 7 days and reaches a nearly-stable value around 0.12 for lags between 50 and 330 days. The all-site prior-parameter error correlation also takes one week to be less than 0.5 , but the decrease is then milder than that of the prior residual correlation, reaching a minimum of 0.05 around the six-month lag. The more persistent autocorrelation of the prior-parameter error can be linked to the small size of the state vector. In our case, as in most optimisation studies (Williams et al., 2009), the number of tuned param-

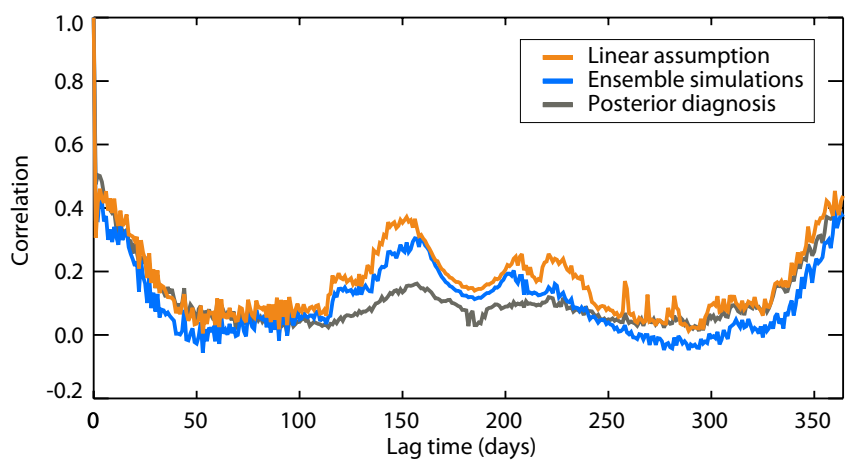

Fig. 2. All-site median of the autocorrelation of the observation error (i.e., model error + measurement error) $\mathbf{R}$, estimated at each site with three methods: prior diagnostics with the linear assumption (orange, $\hat{\mathbf{R}}^{\text {prior }}$ from Eq. 1), prior diagnostics with ensemble simulations (blue, $\hat{\mathbf{R}}^{\text {prior }}$ from Eq. 1), and posterior diagnostics (grey, $\hat{\mathbf{R}}^{\text {post }}$ from Eq. 3)

eters is rather small, which keeps the number of degrees of freedom low.

The correlation of the prior residual error is above that of the prior-parameter error for lags between 120 and 230 days correlation, with in particular a bump around the 150-day lag. This last feature possibly comes from an overestimation of the growing season length in ORCHIDEE: the NEE residual (observation minus simulation) tends to be negative both at the beginning and at the end of the growing season, temporally distant of about 150 days (Kuppel et al., 2012), thus, inducing a positive error correlation. The presence of this bump around the 220-day lag (i.e., the dormant season length) at some of the sites with several years of data records (not shown) further hints in that direction.

The median standard deviation of the prior residual is equal to $2.1 \mathrm{gC} \mathrm{m}^{-2} \mathrm{~d}^{-1}$ when combining the sites altogether, while the median prior-parameter error contributes to an uncertainty of $1.3 \mathrm{gC} \mathrm{m}^{-2} \mathrm{~d}^{-1}$ in the observation space. This latter value is not negligible, which indicates that the current uncertainty on the main model parameters induces a significant uncertainty on the simulated NEE.

\subsection{Temporal structure of the observation error}

The orange curve in Fig. 2 ("linear assumption") shows the corresponding all-site median time correlogram, from the autocorrelation of the observation errors (model + measurement errors) computed at each site. One can notice a very rapid decrease, since after one day the correlation falls to a ten-day long plateau at 0.4 , and then decreases to reach 0.1 after one month. For larger lags, the correlation is mostly negligible although there is a bump almost reaching 0.4 around the 150-day lag and a weaker one around the 220-day lag. These last two features originate from the prior residual error (Sect. 3.1) and are made significant in the observation 
Table 1. Chi-square test after optimisation.

\begin{tabular}{ll}
\hline $\begin{array}{l}\text { Observation error } \\
\text { statistics }\end{array}$ & $\begin{array}{l}\text { All-site median } \\
\chi^{2}\left(2 J\left(x^{\text {post }}\right) / p\right)\end{array}$ \\
\hline Measurement error only: diagonal $\mathbf{R}, \sigma^{2}=0.16$ & 14.6 \\
Diagnosis a priori ( $\left.\hat{\mathbf{R}}^{\text {prior }}\right)$ : diagonal $\mathbf{R}, \sigma^{2}=2.78$ & 1.12 \\
Diagnosis a posteriori $\left(\hat{\mathbf{R}}^{\text {post }}\right)$ : diagonal $\mathbf{R}, \sigma^{2}=3.67$ & 0.64 \\
\hline
\end{tabular}

error by the very low correlation of the prior-parameter error around this lag (Fig. 1). The seasonality of the observation error correlation is also significant, although similar to both the prior residual and the prior-parameter error for large time lags (Sect. 3.1).

The median standard deviation of the observation error is estimated to be $1.7 \mathrm{gC} \mathrm{m}^{-2} \mathrm{~d}^{-1}$. This number combines measurement and model contributions (Sect. 2.3). Using measurements across different types of forest ecosystems, Richardson et al. (2008) found that the random measurement errors range approximately from 0.2 to $0.8 \mathrm{gC} \mathrm{m}^{-2} \mathrm{~d}^{-1}$, being somewhat proportional to the absolute flux magnitude, which means that the variance due to the measurement errors accounts for 1 to $25 \%$ of the total observation variance. Additionally, Lasslop et al. (2008) showed that no significant measurement error correlation remains at the daily time scale. From these elements, we conclude that the seasonal structure of the model error in ORCHIDEE is very similar to that of the observation error described above (the orange curve in Fig. 2), with a standard deviation ranging from 1.5 to $1.7 \mathrm{gC} \mathrm{m}^{-2} \mathrm{~d}^{-1}$. The estimated structure notably indicates that the model error is somewhat correlated across seasons: for instance, any underestimation/overestimation of the NEE in summer or winter remains the following year.

As mentioned in Appendix B, the robustness of the linearity assumption is tested by estimating the prior-parameter error statistics in the observation space (based on Eq. 1) with an ensemble approach at each site. The rest of the prior diagnosis is otherwise the same, and the all-site median of the time correlation of the corresponding observation error is shown by the blue curve in Fig. 2. The structure of the "ensemble" observation error is very close to that diagnosed previously with the "linear" method, although the correlation of the former remains below the latter, and the standard deviation of the "ensemble" observation error is slightly smaller (1.6 $\mathrm{gC} \mathrm{m}^{-2} \mathrm{~d}^{-1}$, not shown). This result indicates that the linearity assumption in the vicinity of the prior-parameter state does not have a significant impact upon the diagnosis presented in this study.

\subsection{Posterior evaluation at site level}

The diagnosed observation error (model + measurement error) statistics are used as prior information for site-scaled inversions of ORCHIDEE parameters at each of the sites de- scribed in Table A1, according to the methodology described in Sect. 2.4. In Fig. 2, the grey curve shows the median time correlogram corresponding to the posterior diagnosis (after the inversions) of the observation error estimated with both prior and posterior residuals (Eq. 3: F). For lags shorter than 100 days or longer than 250 days, there is a remarkable consistency with the observation error statistics diagnosed a priori (orange curve). Elsewhere, it is nearly uncorrelated and only weakly reproduces the two bumps (around the 150-day and 220-day lags) mentioned in the previous section. It indicates that these features are most probably only partially related to the model error. Instead, this particular correlation structure may be present in the structure of the priorparameter error, but is currently ignored due to the priorparameter diagonal assumption made in the inversions. The standard deviation of $\mathbf{F}$ is equal to $1.9 \mathrm{gC} \mathrm{m}^{-2} \mathrm{~d}^{-1}$, somewhat higher than that brought by the prior diagnosis.

Further on, one metric often used to estimate the optimality of an optimisation is based on the relation of statistical expectation notably presented in Tarantola (1987):

$J\left(x^{\text {post }}\right)=p / 2$,

where $\boldsymbol{x}^{\text {post }}$ is the vector of optimised parameters at the minimum of the cost function $J$, and $p$ the number of observations.

This evaluation criterion is applied to the inversions conducted at each site. Table 1 shows the all-site medians of the ratio between the left-hand term and the right-hand term of Eq. (6) (hereafter chi-square ratio), using various observation error statistics. In the first case, we only take the measurement error into account with a diagonal $\mathbf{R}$ with a standard deviation equal to $0.4 \mathrm{gC} \mathrm{m}^{-2} \mathrm{~d}^{-1}$. One can notice that the value of the cost function at its minimum remains much larger than the half the number of observations (Table 1, first row), suggesting that the low prior observation uncertainty puts too much trust in the measured fluxes and, thus, cannot meet the optimality criterion. Second, we consider the observation error diagnosed a priori in the previous section (measurement + model error). We keep $\mathbf{R}$ diagonal here as well, because of the quick drop in the time correlations shown in Fig. 2, and the standard deviation is now equal to $1.7 \mathrm{gC} \mathrm{m}^{-2} \mathrm{~d}^{-1}$. The value of the analysed parameters is affected at most sites, with smaller changes from their prior values (not shown). The chi-square ratio is much more consistent in this case (Table 1, second row), although the value 


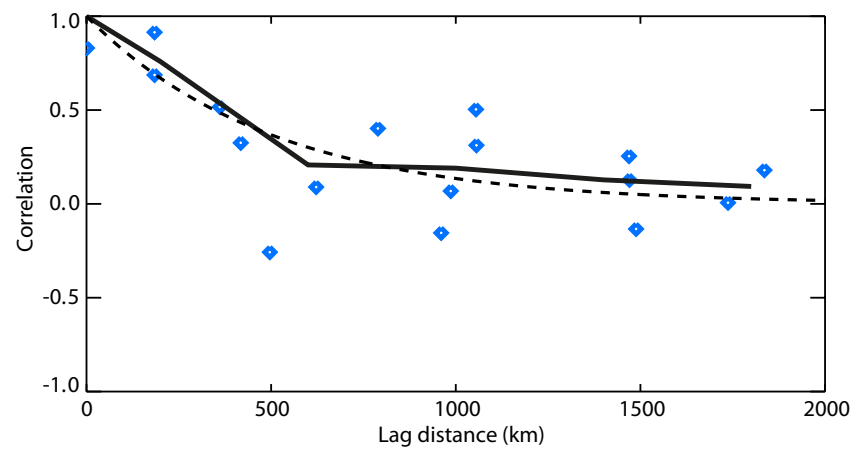

Fig. 3. Distance correlogram of the observation (model+measurement) error $\hat{\mathbf{R}}^{\text {prior }}$ estimated from Eq. (1), using pairs of distant sites for a same time. The value represented by each blue diamond includes all the common years of one site pair. The thick black line represents the overall median using 400-km bins, and the dotted line an exponential decay with an e-folding length of $500 \mathrm{~km}$.

suggests that there is still too much weight put on the observations. Taking advantage of the posterior diagnosis presented above, we now adjust the value of the variance with a standard deviation of $1.9 \mathrm{gC} \mathrm{m}^{-2} \mathrm{~d}^{-1}$. The results show that this first step of an "iterative" estimation of $\mathbf{R}$ significantly improves the optimisation according to the present criterion (Table 1, third row), keeping in mind that the observation error correlations were simply neglected.

\subsection{Spatial structure of the observation error}

The spatial footprint of the observation error without time lag is shown by the distance correlogram in Fig. 3. Note that here we use the posterior diagnosis based on Eq. (3), which provides a better numerical stability than the prior diagnosis of Eq. (1). Each point in Fig. 3 represents a pair of sites that have at least one year of data in common. The all-site median is calculated using $400-\mathrm{km}$ bins. It shows a declining spatial structure of the correlation within the first $500 \mathrm{~km}$, where it remains larger than 0.4 , while it converges toward zero for larger lag distances. Since all sites present the same dominant PFT and since the spatial correlations of the measurement error is considered as negligible, we suggest that the inferred spatial structure of the observation error derives from the model error and that the correlation decline originates from the meteorology. In the next section, this spatial structure is approximated by an exponential decay, with an efolding length of $500 \mathrm{~km}$ in the flux space (black dotted line in Fig. 3).

\subsection{Projection in the space of concentrations}

Assuming similar model-data mismatch across biomes with the ORCHIDEE model (see, for example, Wang et al., 2012), the characteristics of the observation error $\mathbf{R}$ diagnosed in temperate deciduous broadleaf forests (e-folding lengths of $500 \mathrm{~km}$ and 1 day for space and time correlation, respectively) are prescribed at the global scale, and we project the inferred $\hat{\mathbf{R}}^{\text {prior }}$ in the space of atmospheric concentrations using the LMDZ transport model (see Sect. 2.5). For the surface air sample measurements, we find that the median of the standard deviation of the observation error is $1.3 \mathrm{ppm}$ across the 91 sites with a maximum of 8 ppm (at station UTA, Wendover, Utah, USA) and a minimum of $0.1 \mathrm{ppm}$ (at station SMO, Tutuila, American Samoa). No specific spatial structure of this error is seen. For the total column measurements, the standard deviation is $0.5 \mathrm{ppm}$ with a marked spatial structure: an e-folding length of $1200 \mathrm{~km}$ can be deduced from the simulations. We suggest that the total column smoothes out the surface-originated signals, which results in much smaller variances and, thus, much larger correlations. Additionally, for both types of observations there no significant temporal structure of the error, with a nearly-exponential decrease below 0.4 after two days.

\section{Conclusions}

This study proposes a method to diagnose the model structural error in the process-based terrestrial biosphere model ORCHIDEE, based on the information provided by eddycovariance measurements of net carbon fluxes. This term is analogous to the aggregation error that has been rigorously described in atmospheric inversions (Bocquet et al., 2011; Kaminski et al., 2001; Thompson et al., 2011), in that it arises from truncating a given space of variables. As a first step, we have used NEE measurement records at twelve flux tower sites in temperate deciduous broadleaf ecosystems. The statistics of the prior residuals (i.e., measurementsminus-simulations) and the prior-parameter error allowed us to estimate the structure of the observation error (i.e., model error + measurement error) whose inferred characteristics in different observation are summarised in Table 2, and to subsequently derive the model error based on earlier works regarding the flux measurement error.

We find that the model error dominates the observation error budget, with a standard deviation ranging from 1.5 to $1.7 \mathrm{gC} \mathrm{m}^{-2} \mathrm{~d}^{-1}$. The observation error shows some time correlation structure, but rapidly declines beyond the first-day lag so that the assumption of a diagonal observation error covariance matrix within a CCDAS remains realistic. Note, however, an increase of the error correlation at the one year time lag (up to 0.45), currently neglected in most carbon cycle optimisation systems, that may impact the estimated state vector and associated errors in CCDASs. Ensemble simulations show that these results are independent from the assumed linearity of the model in the vicinity of the prior state. A spatial structure is also visible, with a decrease of the correlation in space rather e-folding with a length of about $500 \mathrm{~km}$. Evaluative site-scaled parameters inversions support 
Table 2. Summary of the characteristics of the median observation error (measurement error + model error) in the ORCHIDEE model, projected in several observation spaces.

\begin{tabular}{|c|c|c|c|}
\hline \multirow{2}{*}{ Observation type } & \multicolumn{3}{|c|}{ Structure of the observation error } \\
\hline & $\begin{array}{l}\text { Standard } \\
\text { deviation }\end{array}$ & Time correlation & Space correlation \\
\hline Surface carbon flux (NEE) & $1.7 \mathrm{gC} \mathrm{m}^{-2} \mathrm{~d}^{-1}$ & $\begin{array}{l}\text { Rapid decrease, below } 0.4 \text { after } \\
\text { the first day }\end{array}$ & $\begin{array}{l}\text { Exponential decrease, e-folding } \\
\text { length of } 500 \mathrm{~km}\end{array}$ \\
\hline $\begin{array}{l}\text { Atmospheric } \mathrm{CO}_{2} \text { concentration } \\
\text { (surface sample) }\end{array}$ & $1.3 \mathrm{ppm}$ & $\begin{array}{l}\text { Rapid decrease, below } 0.4 \text { after } \\
\text { the second day }\end{array}$ & No specific structure \\
\hline $\begin{array}{l}\text { Atmospheric } \mathrm{CO}_{2} \text { concentration } \\
\text { (total column) }\end{array}$ & $0.5 \mathrm{ppm}$ & $\begin{array}{l}\text { Rapid decrease, below } 0.4 \text { after } \\
\text { the second day }\end{array}$ & $\begin{array}{l}\text { Exponential decrease, e-folding } \\
\text { length of } 1200 \mathrm{~km}\end{array}$ \\
\hline
\end{tabular}

a consistency between our diagnosis method, based on prior information, and a posterior diagnosis using both the prior and the optimised fluxes. The same inversions also show that the diagnosed standard deviation of the observation error complies fairly well with a common optimality criterion used in data assimilation. We additionally suggest that an iterative use, in successive inversions, of the standard deviation brought by the posterior diagnosis mentioned above could further improve the estimation of the observation uncertainty.

The diagnosed model error is large enough to necessitate an explicit representation in parameter optimisation schemes using NEE measurements in general and in CCDASs in particular. For CCDASs, the observation error also bears consequences on the assimilation of concentration measurements. Our evaluation indicates that it can simply be treated like an additional contribution to the observation error variance of the order of $1 \mathrm{ppm}^{2}$ for most background air sampling stations. For the assimilation of $\mathrm{CO}_{2}$ total column measurements like the GOSAT retrievals, the contribution to the variance is small $\left(0.25 \mathrm{ppm}^{2}\right)$, but its spatial coherence (an efolding length of about $1200 \mathrm{~km}$ ) makes its representation in CCDASs both critical and very challenging. Its characteristics are actually commensurate with those of transport model errors (Chevallier et al., 2010; Houweling et al., 2010) and both concur in hindering the assimilation of $\mathrm{X}_{\mathrm{CO}_{2}}$.

One of the assets of CCDAS is the possibility to run the optimised model outside the data assimilation period, for instance for long-term predictions (e.g., Rayner et al., 2011). In this prediction mode, the model carries its structural error. As a consequence, the forecast error does not converge towards zero when assimilating more informative observations in the parameter optimisation phase. Our method allows quantifying the contribution of the structural model error to the forecast error.

There are four main limitations to this study. First, only one type of ecosystem is presently considered, which may fail to capture specificities of other types of biomes under different climatic conditions. Second, more measurement sites in this ecosystem would be needed to span a larger range of forest species, forest age classes, and soil types in order to derive more robust estimates. Third, it is hard to assess to which extent our results apply to terrestrial biosphere models other than ORCHIDEE. Fourth, the contribution from the meteorological forcing has not been considered in the observation error budget because the forcing is taken from in situ measurements in the simulations, but this component should be considered when applying the present method at coarser scales, i.e., with less known forcing variables. Additionally, the method can be extended to other measurements such as the latent heat flux (LE) and the sensible heat flux $(H)$, which account for the energy budget in process-based biosphere models.

Nonetheless, this work should be considered as an effort toward the estimation of the model structural components of the uncertainty in complex data assimilation systems such as CCDASs, particularly since the method requires few computations (only prior simulations and sensitivity are required) and can easily be applied beyond the present framework.

\section{Appendix A}

Demonstration of Eq. (3) based on Desroziers et al. (2005)

Using the common linear assumption, the optimised state $\boldsymbol{x}^{\text {post }}$ can be decomposed here as follows:

$\boldsymbol{x}^{\text {post }}=\boldsymbol{x}^{\text {prior }}+\delta \boldsymbol{x}^{\text {post }}=\boldsymbol{x}^{\text {prior }}+\mathbf{K} \boldsymbol{d}^{\text {o-post }}$,

where the optimisation increment $\delta \boldsymbol{x}^{\text {post }}$ can be expressed from the residuals of the prior model $\boldsymbol{d}^{\mathrm{o} \text {-prior }}$ using the gain matrix of the optimisation K (Talagrand, 1997):

$\mathbf{K}=\mathbf{B} \mathbf{H}^{\mathrm{T}}\left(\mathbf{H B} \mathbf{H}^{\mathrm{T}}+\mathbf{R}\right)^{-1}$.

Using the relation of Eq. (A1) in Eq. (4), $\boldsymbol{d}^{\mathrm{o} \text {-post }}$ is given by

$$
\begin{aligned}
\boldsymbol{d}^{\mathrm{o}-\text { post }} & =\boldsymbol{y}^{\mathrm{o}}-H\left(\boldsymbol{x}^{\mathrm{prior}}+\mathbf{K} \boldsymbol{d}^{\mathrm{o}-\text { prior }}\right) \\
& =\boldsymbol{y}^{\mathrm{o}}-H\left(\boldsymbol{x}^{\mathrm{prior}}\right)-\mathbf{H K} \boldsymbol{d}^{\mathrm{o}-\text { prior }} \\
& =\boldsymbol{d}^{\mathrm{o}-\text { prior }}-\mathbf{H K} \boldsymbol{d}^{\mathrm{o}-\text { prior }} \\
& =(\mathbf{I}-\mathbf{H K}) \boldsymbol{d}^{\mathrm{o}-\text { prior }}
\end{aligned}
$$


Table A1. Information about the selected FluxNet sites.

\begin{tabular}{llll}
\hline Site & Location & Time period & References \\
\hline DE-Hai & $51.079^{\circ} \mathrm{N}, 10.452^{\circ} \mathrm{E}$ & $2000-2006$ & Mund et al. (2010) \\
DK-Sor & $55.487^{\circ} \mathrm{N}, 11.646^{\circ} \mathrm{E}$ & $2004-2006$ & Pilegaard et al. (2001) \\
FR-Fon & $48.476^{\circ} \mathrm{N}, 2.78^{\circ} \mathrm{E}$ & 2006 & Prevost-Boure et al. (2010) \\
FR-Hes & $48.674^{\circ} \mathrm{N}, 7.064^{\circ} \mathrm{E}$ & $2001-2003$ & Granier et al. (2008) \\
JP-Tak & $36.146^{\circ} \mathrm{N}, 137.423^{\circ} \mathrm{E}$ & $1999-2004$ & Ito et al. (2006) \\
UK-Ham & $51.121^{\circ} \mathrm{N}, 0.861^{\circ} \mathrm{W}$ & $2004-2005$ & http://www.forestry.gov.uk/ \\
& & & website/forestresearch.nsf/ \\
& & & ByUnique/INFD-62NBUH \\
US-Bar & $44.065^{\circ} \mathrm{N}, 71.288^{\circ} \mathrm{W}$ & $2004-2005$ & Jenkins et al. (2007) \\
US-Ha1 & $42.538^{\circ} \mathrm{N}, 72.172^{\circ} \mathrm{W}$ & $2003-2006$ & Urbanski et al. (2007) \\
US-LPH & $42.542^{\circ} \mathrm{N}, 72.185^{\circ} \mathrm{W}$ & $2003-2004$ & Hadley et al. (2008) \\
US-MOz & $38.744^{\circ} \mathrm{N}, 92.2^{\circ} \mathrm{W}$ & $2005-2006$ & Gu et al. (2012) \\
US-UMB & $45.56^{\circ} \mathrm{N}, 84.714^{\circ} \mathrm{W}$ & $2000-2003$ & Gough et al. (2008) \\
US-WCr & $45.806^{\circ} \mathrm{N}, 90.08^{\circ} \mathrm{W}$ & $1999-2004$ & Cook et al. (2004) \\
\hline
\end{tabular}

where $\mathbf{I}$ is the identity matrix. Then, the use of Eq. (A2) gives

$$
\begin{aligned}
\boldsymbol{d}^{\mathrm{o}-\text { post }} & =\boldsymbol{I}-\mathbf{H B H}^{\mathrm{T}}\left(\mathbf{H B H} \mathbf{H}^{\mathrm{T}}+\mathbf{R}\right)^{-1} \boldsymbol{d}^{\mathrm{o}-\text { prior }} \\
& =\left(\left(\mathbf{H B H} \mathbf{H}^{\mathrm{T}}+\mathbf{R}\right)\left(\mathbf{H B H} \mathbf{H}^{\mathrm{T}}+\mathbf{R}\right)^{-1}\right. \\
& \left.-\mathbf{H B H} \mathbf{H}^{\mathrm{T}}\left(\mathbf{H B H} \mathbf{H}^{\mathrm{T}}+\mathbf{R}\right)^{-1}\right) \boldsymbol{d}^{\mathrm{o}-\text { prior }} \\
& =\mathbf{R}\left(\mathbf{H B} \mathbf{H}^{\mathrm{T}}+\mathbf{R}\right)^{-1} \boldsymbol{d}^{\mathrm{o} \text {-prior }},
\end{aligned}
$$

then the covariance between the distribution of $d^{\text {o-post }}$ and $\boldsymbol{d}^{\mathrm{o}-\text { prior }}, \mathbf{F}$, can be expressed as

$\mathbf{F}=\mathbf{R}\left(\mathbf{H B H} \mathbf{H}^{\mathrm{T}}+\mathbf{R}\right)^{-1} \mathbf{D}$,

which, from Eq. (1), simplifies to

$\mathbf{F}=\mathbf{R}$.

\section{Appendix B}

\section{Application of the diagnoses to the FLUXNET data}

We first apply the prior and posterior diagnoses, respectively, described by Eqs. (1) and (3) to derive the spatial structure of the observation error (i.e., model error + measurement error) covariance matrix at each observation site, using observations serially distributed over time. Considering daily observations of NEE, the term of coordinates $(i, j)$ of a given error covariance matrix expresses the covariance between days $i$ and $j$, with a time lag equal to $|i-j|$ days (all the terms of one diagonal account for equally-lagged covariances). Given the limited number of observations available at some sites, $\mathbf{D}$ and $\mathbf{F}$ are calculated at each site as diagonal-constant matrices (Toeplitz matrices), assuming stationary errors. If the main diagonal is called the first diagonal, the $(t+1)$-th diagonal of $\mathbf{D}$ (resp. F) is then defined by a single term $D_{t}$ (resp. $F_{t}$ ) equal to the $t$-lagged covariance:

$$
\begin{aligned}
D_{t} & =\frac{1}{N-t}\left(\left(\boldsymbol{d}^{\mathrm{o}-\text { prior }}\right)_{1 \leq k \leq N-t}\right)^{\mathrm{T}}\left(\left(\boldsymbol{d}^{\mathrm{o}-\text { prior }}\right)_{t \leq k \leq N}\right), \\
F_{t} & =\frac{1}{N-t}\left(\left(\boldsymbol{d}^{\mathrm{o}-\text { prior }}\right)_{1 \leq k \leq N-t}\right)^{\mathrm{T}}\left(\left(\boldsymbol{d}^{\mathrm{o}-\text { post }}\right)_{t \leq k \leq N}\right),
\end{aligned}
$$

where $N$ and $\left(\boldsymbol{d}^{\mathrm{x}}\right)_{t 1 \leq k \leq t 2}$ are, respectively, the dimension of the residuals and the sub-vector of $\boldsymbol{d}^{\mathrm{x}}$ taken between chronological indexes $t 1$ and $t 2$. Note that the relative shortness of the time series available at each site, with respect to the time scales of some biophysical processes (such as soil carbon storage), makes it difficult to identify any systematic (longterm) bias in the residuals. To circumvent this problem and following Desroziers et al. (2005), we compute mean squares rather than standard deviations in Eqs. (B1) and (B2).

For consistency, we also reduce the full $\mathbf{H B H}^{\mathrm{T}}$ matrix to a diagonal-constant matrix at each site, by averaging along each diagonal:

$$
\mathbf{H B H}_{t}^{\mathrm{T}}=\frac{1}{N-t} \sum_{\mathrm{k}=1}^{N-t}\left(\mathbf{H B H}^{\mathrm{T}}\right)_{k, k+t},
$$

where $\left(\mathbf{H B H}^{\mathrm{T}}\right)_{k, k+t}$ are the elements of the $(t+1)$-th diagonal in the lower half of the original $\mathbf{H B H}^{\mathrm{T}}$. This matrix HBH $^{\mathrm{T}}$ can also be obtained a simple ensemble method applied at each site, avoiding the linearity assumption. Instead of using the sandwich product $\mathbf{H B H}^{\mathrm{T}}$, in this case we use the statistics provided by a large ensemble of model simulations (500 members) with a parameter distribution that follows the statistics of $\mathbf{B}$ around the prior values.

Both matrices $\hat{\mathbf{R}}^{\text {prior }}$ and $\hat{\mathbf{R}}^{\text {post }}$ are calculated as diagonalconstant. For each lag $t$,

$$
\begin{aligned}
\hat{\mathbf{R}}_{t}^{\text {prior }} & =D_{t}-\mathbf{H B H}_{t}^{\mathrm{T}} . \\
\hat{\mathbf{R}}_{t}^{\text {post }} & =F_{t} .
\end{aligned}
$$


Table B1. Parameters of the state vector $\boldsymbol{x}$, with their prior value, variation range and uncertainty.

\begin{tabular}{|c|c|c|c|c|}
\hline Parameter & Description & Prior value & Range & $\sigma_{\text {prior }}$ \\
\hline$V_{\text {cmax }}$ & Maximum carboxylation rate $\left(\mu \mathrm{mol} \mathrm{m}{ }^{-2} \mathrm{~s}^{-1}\right)$ & 55 & $30-80$ & 8.33 \\
\hline$G_{\mathrm{S}, \text { slope }}$ & Ball-Berry slope & 9 & $6-12$ & 1 \\
\hline$c_{T, \mathrm{opt}}$ & Factor controlling optimal photosynthesis temperature $\left({ }^{\circ} \mathrm{C}\right)$ & 26 & $18-34$ & 2.67 \\
\hline$c_{T, \min }$ & Factor controlling minimal photosynthesis temperature $\left({ }^{\circ} \mathrm{C}\right)$ & -2 & $(-7)-3$ & 1.67 \\
\hline$c_{T, \max }$ & Factor controlling maximal photosynthesis temperature $\left({ }^{\circ} \mathrm{C}\right)$ & 38 & $33-43$ & 1.67 \\
\hline SLA & Specific leaf area $\left(\mathrm{m}^{2} \mathrm{~g}^{-1}\right)$ & 0.026 & $0.013-0.05$ & 0.015 \\
\hline $\mathrm{LAI}_{\mathrm{MAX}}$ & Maximum LAI per PFT $\left(\mathrm{m}^{2} \mathrm{~m}^{-2}\right)$ & 5 & $3-8$ & 0.83 \\
\hline$K_{\text {lai.happy }}$ & LAI threshold to stop carbohydrate use & 0.5 & $0.15-0.7$ & 0.09 \\
\hline$K_{\text {pheno,crit }}$ & Multiplicative factor for growing season start threshold & 1 & $0.5-2$ & 0.25 \\
\hline$c_{T, \text { senescence }}$ & Offset for temperature threshold for senescence $\left({ }^{\circ} \mathrm{C}\right)$ & 12 & 6-18 & 2 \\
\hline$L_{\text {agecrit }}$ & Average critical age for leaves (days) & 180 & $120-240$ & 20 \\
\hline Hum $_{\text {cste }}$ & Parameter describing the exponential root profile & 0.8 & $0.2-3$ & 0.47 \\
\hline $\mathrm{Dpu}_{\mathrm{cste}}$ & Total depth of soil water pool (m) & 2 & $0.2-10$ & 1.63 \\
\hline$F_{\text {stressh }}$ & Factor controlling threshold of soil water content to open stomatas & 6 & $2-10$ & 1.33 \\
\hline$Q 10$ & Temperature dependence of heterotrophic respiration & 1.99372 & $1-3$ & 0.33 \\
\hline$K_{\text {SoilC }}$ & Multiplicative factor of initial carbon pools & 1 & $0.1-2$ & 0.32 \\
\hline $\mathrm{HR}_{H, a}$ & Factor of the humidity dependence of heterotrophic respiration & -1.1 & $-1.4-(-0.8)$ & 0.1 \\
\hline $\mathrm{HR}_{H, b}$ & Factor of the humidity dependence of heterotrophic respiration & 2.4 & $2.1-2.7$ & 0.1 \\
\hline $\mathrm{HR}_{H, c}$ & Factor of the humidity dependence of heterotrophic respiration & -0.29 & $-0.59-0.01$ & 0.1 \\
\hline $\mathrm{HR}_{H, \min }$ & Factor of the humidity dependence of heterotrophic respiration & 0.25 & $0.1-0.6$ & 0.083 \\
\hline $\mathrm{MR}_{a}$ & Slope of the relationship between temperature and maintenance respiration & 0.16 & $0.08-0.24$ & 0.027 \\
\hline $\mathrm{MR}_{b}$ & Intercept of the relationship between temperature and maintenance respiration & 1 & $0.5-2$ & 0.25 \\
\hline $\mathrm{GR}_{\text {frac }}$ & Fraction of biomass available for growth that is respired & 0.28 & $0.2-0.36$ & 0.027 \\
\hline$Z_{\text {decomp }}$ & Parameter describing the profile of organic matter content in the soil & 0.2 & $0.1-1.5$ & 0.23 \\
\hline$Z 0_{\text {overheight }}$ & Characteristic rugosity length $(\mathrm{m})$ & 0.0625 & $0.02-0.1$ & 0.013 \\
\hline$K_{\text {albedo,veg }}$ & Multiplying factor for surface albedo & 1 & $0.8-1.2$ & 0.067 \\
\hline
\end{tabular}

Then, we adapt Eqs. (B1) and (B3) to the spatial domain by combining statistics between all the sites, using observations simultaneously made at each site. Considering two locations $A$ and $B$, spatially distant of $d$, with intersecting simulation/measurements time periods, we apply the prior diagnosis based on Eq. (1):

$$
\begin{aligned}
D_{d} & =\frac{1}{N_{A B}}\left(\boldsymbol{d}_{A}^{\mathrm{o}-\text { prior }}\right)^{\mathrm{T}} \boldsymbol{d}_{B}^{\mathrm{o}-\text { prior }}, \\
\mathbf{H B H}_{d}^{\mathrm{T}} & =\frac{1}{N_{A B}} \sum_{\mathrm{k}=1}^{N_{A B}}\left(\mathbf{H B H}_{A B}^{\mathrm{T}}\right)_{k, k}, \\
\hat{R}_{d} & =D_{d}-\mathbf{H B H}_{d}^{\mathrm{T}}
\end{aligned}
$$

where $\boldsymbol{d}_{A}^{\mathrm{o}-\text { prior }}$ and $\boldsymbol{d}_{B}^{\mathrm{o}-\text { prior }}$ are the two vectors of prior residuals chronologically subsampled within their temporal intersection, $N_{A B}$ is the number of intersecting observations, and $\mathbf{H B H}_{A B}^{\mathrm{T}}$ is the sub-matrix of $\mathbf{H B H} \mathbf{H}^{\mathrm{T}}$ expressing the prior error statistics between $A$ and $B$ within their temporal intersection. Indeed, a single all-site $\mathbf{H B H}^{\mathrm{T}}$ is here computed, using a "multi-site" approach where a single common set of parameters simultaneously describes the prior state at all 12 sites (Kuppel et al., 2012).
Acknowledgements. This work has been supported by the French Agence Nationale pour la Recherche (project MSDAG) and by the CARBONES project within the EU's 7th Framework Programme for Research and Development. The Ph.D. programme of S. Kuppel has been funded by the Commissariat à l'Energie Atomique et aux Energies Alternatives (CEA). The sites PIs of DE-Hai, DK-Sor, FR-Fon, FR-Hes, JP-Tak, UK-Ham, US-Bar, US-Ha1, US-LPH, US-MOz, US-UMB and US-WCr are thanked for making their data available. The authors would like to acknowledge the work of the NASA ACOS project to create the $X_{\mathrm{CO}_{2}}$ data. This work was performed using HPC resources from DSM-CCRT and [CCRT/CINES/IDRIS] under the allocation 2012-t2012012201 made by GENCI (Grand Equipement National de Calcul Intensif) and by local computer resources of LSCE.

\section{Edited by: J. Annan}

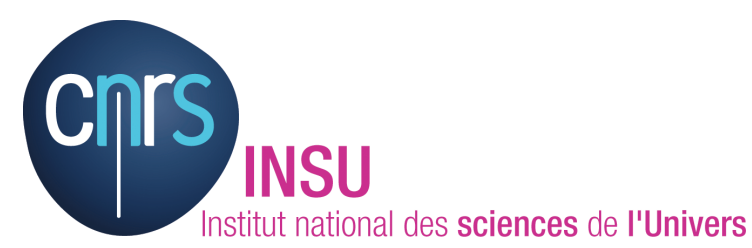

The publication of this article is financed by CNRS-INSU. 


\section{References}

Aubinet, M., Grelle, A., Ibrom, A., Rannik, U., Moncrieff, J., Foken, T., Kowalski, A. S., Martin, P. H., Berbigier, P., Bernhofer, C., Clement, R., Elbers, J., Granier, A., Grunwald, T., Morgenstern, K., Pilegaard, K., Rebmann, C., Snijders, W., Valentini, R., and Vesala, T.: Estimates of the annual net carbon and water exchange of forests: The EUROFLUX methodology, Adv. Ecol. Res., 30, 113-175, 2000.

Baldocchi, D.: Breathing of the terrestrial biosphere: lessons learned from a global network of carbon dioxide flux measurement systems, Austr. J. Botany, 56, 1-26, doi:10.1071/Bt07151, 2008.

Baldocchi, D., Falge, E., Gu, L. H., Olson, R., Hollinger, D., Running, S., Anthoni, P., Bernhofer, C., Davis, K., Evans, R., Fuentes, J., Goldstein, A., Katul, G., Law, B., Lee, X. H., Malhi, Y., Meyers, T., Munger, W., Oechel, W., Paw, K. T., Pilegaard, K., Schmid, H. P., Valentini, R., Verma, S., Vesala, T., Wilson, K., and Wofsy, S.: FLUXNET: A new tool to study the temporal and spatial variability of ecosystem-scale carbon dioxide, water vapor, and energy flux densities, B. Am. Meteorol. Soc., 82, 2415-2434, 2001.

Bocquet, M., Wu, L., and Chevallier, F.: Bayesian design of control space for optimal assimilation of observations, Part I: Consistent multiscale formalism, Q. J. Roy. Meteorol. Soc., 137, 13401356, doi:10.1002/Qj.837, 2011.

Chevallier, F., Breon, F. M., and Rayner, P. J.: Contribution of the Orbiting Carbon Observatory to the estimation of $\mathrm{CO}(2)$ sources and sinks: Theoretical study in a variational data assimilation framework, J. Geophys. Res.-Atmos., 112, D09307, doi:10.1029/2006jd007375, 2007.

Chevallier, F., Feng, L. A., Bosch, H., Palmer, P. I., and Rayner, P. J.: On the impact of transport model errors for the estimation of $\mathrm{CO}(2)$ surface fluxes from GOSAT observations, Geophys. Res. Lett., 37, L21803, doi:10.1029/2010g1044652, 2010.

Chevallier, F., Deutscher, N. M., Conway, T. J., Ciais, P., Ciattaglia, L., Dohe, S., Frohlich, M., Gomez-Pelaez, A. J., Griffith, D., Hase, F., Haszpra, L., Krummel, P., Kyro, E., Labuschagne, C., Langenfelds, R., Machida, T., Maignan, F., Matsueda, H., Morino, I., Notholt, J., Ramonet, M., Sawa, Y., Schmidt, M., Sherlock, V., Steele, P., Strong, K., Sussmann, R., Wennberg, P., Wofsy, S., Worthy, D., Wunch, D., and Zimnoch, M.: Global $\mathrm{CO}(2)$ fluxes inferred from surface air-sample measurements and from TCCON retrievals of the $\mathrm{CO}(2)$ total column, Geophys. Res. Lett., 38, L24810, doi:10.1029/2011g1049899, 2011.

Crisp, D., Fisher, B. M., O’Dell, C., Frankenberg, C., Basilio, R., Bösch, H., Brown, L. R., Castano, R., Connor, B., Deutscher, N. M., Eldering, A., Griffith, D., Gunson, M., Kuze, A., Mandrake, L., McDuffie, J., Messerschmidt, J., Miller, C. E., Morino, I., Natraj, V., Notholt, J., O’Brien, D. M., Oyafuso, F., Polonsky, I., Robinson, J., Salawitch, R., Sherlock, V., Smyth, M., Suto, H., Taylor, T. E., Thompson, D. R., Wennberg, P. O., Wunch, D., and Yung, Y. L.: The ACOS $\mathrm{CO}_{2}$ retrieval algorithm - Part II: Global $\mathrm{X}_{\mathrm{CO}_{2}}$ data characterisation, Atmos. Meas. Tech., 5, 687-707, doi:10.5194/amt-5-687-2012, 2012.

Cook, B. D., Davis, K. J., Wang, W. G., Desai, A., Berger, B. W., Teclaw, R. M., Martin, J. G., Bolstad, P. V., Bakwin, P. S., Yi, C. X., and Heilman, W.: Carbon exchange and venting anomalies in an upland deciduous forest in northern Wisconsin, USA, Agr. Forest Meteorol., 126, 271-295, doi:10.1016/j.agrformet.2004.06.008, 2004.

Desroziers, G., Berre, L., Chapnik, B., and Poli, P.: Diagnosis of observation, background and analysis-error statistics in observation space, Q. J. Roy. Meteorol. Soc., 131, 3385-3396, doi:10.1256/Qj.05.108, 2005.

Gough, C. M., Vogel, C. S., Schmid, H. P., and Curtis, P. S.: Controls on annual forest carbon storage: Lessons from the past and predictions for the future, Bioscience, 58, 609-622, doi:10.1641/B580708, 2008.

Granier, A., Breda, N., Longdoz, B., Gross, P., and Ngao, J.: Ten years of fluxes and stand growth in a young beech forest at Hesse, North-eastern France, Ann. Forest Sci., 65, 704-740, doi:10.1051/forest:2008052, 2008.

Gu, L. H., Massman, W. J., Leuning, R., Pallardy, S. G., Meyers, T., Hanson, P. J., Riggs, J. S., Hosman, K. P., and Yang, B.: The fundamental equation of eddy covariance and its application in flux measurements, Agr. Forest Meteorol., 152, 135-148, doi:10.1016/j.agrformet.2011.09.014, 2012.

Gurney, K. R., Law, R. M., Denning, A. S., Rayner, P. J., Baker, D., Bousquet, P., Bruhwiler, L., Chen, Y. H., Ciais, P., Fan, S., Fung, I. Y., Gloor, M., Heimann, M., Higuchi, K., John, J., Maki, T., Maksyutov, S., Masarie, K., Peylin, P., Prather, M., Pak, B. C., Randerson, J., Sarmiento, J., Taguchi, S., Takahashi, T., and Yuen, C. W.: Towards robust regional estimates of $\mathrm{CO}_{2}$ sources and sinks using atmospheric transport models, Nature, 415, 626630, 2002.

Hadley, J. L., Kuzeja, P. S., Daley, M. J., Phillips, N. G., Mulcahy, T., and Singh, S.: Water use and carbon exchange of red oak- and eastern hemlock-dominated forests in the northeastern USA: implications for ecosystem-level effects of hemlock woolly adelgid, Tree Physiol., 28, 615-627, 2008.

Hourdin, F., Musat, I., Bony, S., Braconnot, P., Codron, F., Dufresne, J. L., Fairhead, L., Filiberti, M. A., Friedlingstein, P., Grandpeix, J. Y., Krinner, G., Levan, P., Li, Z. X., and Lott, F.: The LMDZ4 general circulation model: climate performance and sensitivity to parametrized physics with emphasis on tropical convection, Clim. Dynam., 27, 787-813, doi:10.1007/s00382006-0158-0, 2006.

Houweling, S., Aben, I., Breon, F.-M., Chevallier, F., Deutscher, N., Engelen, R., Gerbig, C., Griffith, D., Hungershoefer, K., Macatangay, R., Marshall, J., Notholt, J., Peters, W., and Serrar, S.: The importance of transport model uncertainties for the estimation of $\mathrm{CO}_{2}$ sources and sinks using satellite measurements, Atmos. Chem. Phys., 10, 9981-9992, doi:10.5194/acp-10-99812010, 2010.

Ito, A., Muraoka, H., Koizumi, H., Saigusa, N., Murayama, S., and Yamamoto, S.: Seasonal variation in leaf properties and ecosystem carbon budget in a cool-temperate deciduous broad-leaved forest: simulation analysis at Takayama site, Japan, Ecol. Res., 21, 137-149, doi:10.1007/s11284-005-0100-7, 2006.

Jenkins, J. P., Richardson, A. D., Braswell, B. H., Ollinger, S. V., Hollinger, D. Y., and Smith, M. L.: Refining lightuse efficiency calculations for a deciduous forest canopy using simultaneous tower-based carbon flux and radiometric measurements, Agr. Forest Meteorol., 143, 64-79, doi:10.1016/j.agrformet.2006.11.008, 2007.

Kaminski, T., Rayner, P. J., Heimann, M., and Enting, I. G.: On aggregation errors in atmospheric transport inversions, J. Geophys. Res.-Atmos., 106, 4703-4715, 2001. 
Kaminski, T., Knorr, W., Rayner, P. J., and Heimann, M.: Assimilating atmospheric data into a terrestrial biosphere model: A case study of the seasonal cycle, Global Biogeochem. Cy., 16, 1066, doi:10.1029/2001gb001463, 2002.

Kaminski, T., Knorr, W., Scholze, M., Gobron, N., Pinty, B., Giering, R., and Mathieu, P.-P.: Consistent assimilation of MERIS FAPAR and atmospheric $\mathrm{CO}_{2}$ into a terrestrial vegetation model and interactive mission benefit analysis, Biogeosciences, 9, 3173-3184, doi:10.5194/bg-9-3173-2012, 2012.

Kato, T., Scholze, M., Knorr, W., Veenendaal, E., Kaminski, T., Kattge, J., and Gobron, N.: Simultaneous assimilation of satellite and eddy covariance data for improving terrestrial water and carbon simulations at a semi-arid woodland site in Botswana, Biogeosciences Discuss., 9, 3615-3643, doi:10.5194/bgd-9-36152012, 2012.

Knorr, W., Kaminski, T., Scholze, M., Gobron, N., Pinty, B., Giering, R., and Mathieu, P. P.: Carbon cycle data assimilation with a generic phenology model, J. Geophys. Res.-Biogeosci., 115, G04017, doi:10.1029/2009jg001119, 2010.

Krinner, G., Viovy, N., de Noblet-Ducoudre, N., Ogee, J., Polcher, J., Friedlingstein, P., Ciais, P., Sitch, S., and Prentice, I. C.: A dynamic global vegetation model for studies of the coupled atmosphere-biosphere system, Global Biogeochem. Cy., 19, Gb1015, doi:10.1029/2003gb002199, 2005.

Kuppel, S., Peylin, P., Chevallier, F., Bacour, C., Maignan, F., and Richardson, A. D.: Constraining a global ecosystem model with multi-site eddy-covariance data, Biogeosciences, 9, 3757-3776, doi:10.5194/bg-9-3757-2012, 2012.

Lasslop, G., Reichstein, M., Kattge, J., and Papale, D.: Influences of observation errors in eddy flux data on inverse model parameter estimation, Biogeosciences, 5, 1311-1324, doi:10.5194/bg5-1311-2008, 2008.

Mund, M., Kutsch, W. L., Wirth, C., Kahl, T., Knohl, A., Skomarkova, M. V., and Schulze, E. D.: The influence of climate and fructification on the inter-annual variability of stem growth and net primary productivity in an old-growth, mixed beech forest, Tree Physiol., 30, 689-704, doi:10.1093/treephys/tpq027, 2010.

O’Dell, C. W., Connor, B., Bösch, H., O’Brien, D., Frankenberg, C., Castano, R., Christi, M., Eldering, D., Fisher, B., Gunson, M., McDuffie, J., Miller, C. E., Natraj, V., Oyafuso, F., Polonsky, I., Smyth, M., Taylor, T., Toon, G. C., Wennberg, P. O., and Wunch, D.: The $\operatorname{ACOS~} \mathrm{CO}_{2}$ retrieval algorithm - Part 1: Description and validation against synthetic observations, Atmos. Meas. Tech., 5, 99-121, doi:10.5194/amt-5-99-2012, 2012.

Papale, D., Reichstein, M., Aubinet, M., Canfora, E., Bernhofer, C., Kutsch, W., Longdoz, B., Rambal, S., Valentini, R., Vesala, T., and Yakir, D.: Towards a standardized processing of Net Ecosystem Exchange measured with eddy covariance technique: algorithms and uncertainty estimation, Biogeosciences, 3, 571-583, doi:10.5194/bg-3-571-2006, 2006.

Pilegaard, K., Hummelshoj, P., Jensen, N. O., and Chen, Z.: Two years of continuous $\mathrm{CO}_{2}$ eddy-flux measurements over a Danish beech forest, Agr. Forest Meteorol., 107, 29-41, 2001.

Prevost-Boure, N. C., Soudani, K., Damesin, C., Berveiller, D., Lata, J. C., and Dufrene, E.: Increase in aboveground fresh litter quantity over-stimulates soil respiration in a temperate deciduous forest, Appl. Soil Ecol., 46, 26-34, doi:10.1016/j.apsoil.2010.06.004, 2010.
Rayner, P. J., Scholze, M., Knorr, W., Kaminski, T., Giering, R., and Widmann, H.: Two decades of terrestrial carbon fluxes from a carbon cycle data assimilation system (CCDAS), Global Biogeochem. Cy., 19, Gb2026, doi:10.1029/2004gb002254, 2005.

Rayner, P. J., Koffi, E., Scholze, M., Kaminski, T., and Dufresne, J. L.: Constraining predictions of the carbon cycle using data, Philos. Trans. Roy. Soc., 369, 1955-1966, doi:10.1098/rsta.2010.0378, 2011.

Richardson, A. D., Mahecha, M. D., Falge, E., Kattge, J., Moffat, A. M., Papale, D., Reichstein, M., Stauch, V. J., Braswell, B. H., Churkina, G., Kruijt, B., and Hollinger, D. Y.: Statistical properties of random $\mathrm{CO}_{2}$ flux measurement uncertainty inferred from model residuals, Agr. Forest Meteorol., 148, 38-50, doi:10.1016/j.agrformet.2007.09.001, 2008.

Santaren, D., Peylin, P., Viovy, N., and Ciais, P.: Optimizing a process-based ecosystem model with eddy-covariance flux measurements: A pine forest in southern France, Global Biogeochem. Cy., 21, Gb2013, doi:10.1029/2006gb002834, 2007.

Scholze, M., Kaminski, T., Rayner, P., Knorr, W., and Giering, R.: Propagating uncertainty through prognostic carbon cycle data assimilation system simulations, J. Geophys. Res.-Atmos., 112, D17305, doi:10.1029/2007jd008642, 2007.

Talagrand, O.: Assimilation of observations, an introduction, J. Meteorol. Soc. Jpn., 75, 191-209, 1997.

Tarantola, A.: Inverse problem theory : methods for data fitting and model parameter estimation, Elsevier, New York, 613 pp., 1987.

Thompson, R. L., Gerbig, C., and Rödenbeck, C.: A Bayesian inversion estimate of $\mathrm{N}_{2} \mathrm{O}$ emissions for western and central Europe and the assessment of aggregation errors, Atmos. Chem. Phys., 11, 3443-3458, doi:10.5194/acp-11-3443-2011, 2011.

Urbanski, S., Barford, C., Wofsy, S., Kucharik, C., Pyle, E., Budney, J., McKain, K., Fitzjarrald, D., Czikowsky, M., and Munger, J. W.: Factors controlling $\mathrm{CO}(2)$ exchange on timescales from hourly to decadal at Harvard Forest, J. Geophys. Res.-Biogeosci., 112, G02020, doi:10.1029/2006jg000293, 2007.

Verbeeck, H., Peylin, P., Bacour, C., Bonal, D., Steppe, K., and Ciais, P.: Seasonal patterns of $\mathrm{CO}(2)$ fluxes in Amazon forests: Fusion of eddy covariance data and the ORCHIDEE model, J. Geophys. Res.-Biogeosci., 116, G02018, doi:10.1029/2010jg001544, 2011.

Wang, T., Brender, P., Ciais, P., Piao, S., Mahecha, M. D., Chevallier, F., Reichstein, M., Ottlé, C., Maignan, F., Arain, A., Bohrer, G., Cescatti, A., Kiely, G., Law, B. E., Lutz, M., Montagnani, L., Moors, E., Osborne, B., Panferov, O., Papale, D., and Vaccari, F. P.: State-dependent errors in a land surface model across biomes inferred from eddy covariance observations on multiple timescales, Ecol. Modell., 246, 11-25, doi:10.1016/j.ecolmodel.2012.07.017, 2012.

Williams, M., Richardson, A. D., Reichstein, M., Stoy, P. C., Peylin, P., Verbeeck, H., Carvalhais, N., Jung, M., Hollinger, D. Y., Kattge, J., Leuning, R., Luo, Y., Tomelleri, E., Trudinger, C. M., and Wang, Y. -P.: Improving land surface models with FLUXNET data, Biogeosciences, 6, 1341-1359, doi:10.5194/bg-6-1341-2009, 2009.

Wunch, D., Toon, G. C., Blavier, J. F. L., Washenfelder, R. A., Notholt, J., Connor, B. J., Griffith, D. W. T., Sherlock, V., and Wennberg, P. O.: The Total Carbon Column Observing Network, Philos. Trans. Roy. Soc., 369, 2087-2112, doi:10.1098/rsta.2010.0240, 2011. 